\title{
$\mathrm{SCB}$ 액비 처리량에 따른 백합나무의 생장 및 바이오에탄올 생산 ${ }^{* 1}$
}

김 호 용*2 - 곽 기 섭*2 - 김 혜 연*2 - 유 근 옥*3 - 김 판 기*4 - 조 도 현*3 . 최 진 용*5,6 최 인 규 ${ }^{2,6 \dagger}$

\section{Effect of Treatment Amounts of Slurry Composting and Biofiltration Liquid Fertilizer on Growth Characteristics and Bioethanol Production of Yellow Poplar*1}

\author{
Ho-Yong Kim*2 ${ }^{2}$ Ki-Seob Gwak ${ }^{* 2} \cdot$ Hye-Yun Kim*2 ${ }^{2}$ Keun-Ok Ryu*3 ${ }^{*}$ \\ Pan-Gi Kim*4 ${ }^{* 4}$ Do-Hyun Cho*3 $\cdot$ Jin-Yong Choi*5,6 $\cdot$ In-Gyu Choi*2,6† \\ 요 약
}

$\mathrm{SCB}$ 액비 처리가 백합나무의 생장에 미치는 영향을 조사하고 수확된 백합나무를 원료로 한 바이오에탄올 생 산량 비교를 위하여, 처리량별로 처리구를 설정하고 상대 생장량, 바이오매스 생장량, 엽특성 및 구성당과 에탄 올 생산량을 각각 분석하였다. SCB액비 처리를 통해 백합나무의 바이오매스 생장량 $(64.67 \%)$ 및 Glucose 함량 $(6.07 \%)$ 이 증가하였고 이는 $\mathrm{SCB}$ 액비에 함유된 양료 성분과 수분 함량이 엽록소 생산에 영향을 끼쳤기 때문으 로 사료된다. 바이오에탄올 생산에 앞서 $\mathrm{SCB}$ 액비 처리되어 생장한 백합나무를 유기용매 전처리 및 약산 전처리 를 하였으며 반응 온도 $\left(150^{\circ} \mathrm{C}\right)$, 승온 시간 $(40$ 분), 반응 시간(10분)은 모두 동일하게 진행하였다. 전처리 효율은 중 처리구를 유기용매 전처리 (w/ $1 \%$ 황산) 하였을 때 잔여율이 $44.81 \%$ 로 가장 높았으며, 치환성 양이온이 전처 리 효과를 증진시킨 것으로 보인다. 전처리 된 시료를 동시당화발효하여 바이오에탄올을 생산하였으며 초기 투 입량 대비 가장 높은 에탄올 생산 수율은 대 처리구에서 얻을 수 있었으나 $(16.11 \%)$, 바이오매스 생산량을 고려 하면 중 처리구의 에탄올 생산량이 가장 많았으며, 대조구 대비 $72.93 \%$ 증가하였다.

*1 접수 2011년 7월 28일, 채택 2011년 8월 18일

*2 서울대학교 농업생명과학대학 산림과학부. Department of Forest Sciences, Seoul National University, Seoul 151-921, Korea

*3 국립산림과학원 산림자원육성부. Korea Forest Research Institute, Seoul 130-712, Korea

*4 경북대학교 생태환경대학 생태환경시스템학부. Department of Forest Resources and Environment, Kyungpook National University, Sangju 742-711, Korea

*5 서울대학교 농업생명과학대학 조경-지역시스템공학부, Department of Landscape Architecture and Rural System Engineering, Seoul National University, Seoul 151-921, Korea

*6 서울대학교 농업생명과학대학 농업생명과학연구원, Research Institute for Agriculture and Life Sciences, College of Agriculture and Life Sciences, Seoul National University, Seoul 151-921, Korea

† 교신저자(corresponding author) : 최인규(e-mail: cingyu@snu.ac.kr) 


\begin{abstract}
The main purpose of this study was to examine the influence of treatment amounts of Slurry Composting and Biofiltration liquid fertilizer (SCBLF) on biomass growth of Yellow poplar (Liriodendron tulipifera) and to compare bioethanol production from the harvested wood. Relative growth rate, biomass production and leaf characteristics were significantly enhanced by SCBLF treatment and medium treatment plot showed highest value. Nitrogen compounds and water content in SCBLF affected to increase chlorophyll contents which led improving biomass production (64.67\%) and glucose contents (6.07\%) than control. Organosolv and dilute acid pretreatments were preliminarily carried for bioethanol production, and the pretreatment processes were conducted at all the same solid to liquid ratio $(1: 10)$, reaction temperature $\left(150^{\circ} \mathrm{C}\right)$, preheating time ( $40 \mathrm{~min})$ and residence time $(10 \mathrm{~min})$. The water insoluble solid recovery of Organosolv pretreatment with $1 \%$ sulfuric acid as a catalyst was the lowest and that of medium treatment plot was $44.81 \%$. Exchangeable cations in SCBLF might be affected to increase pretreatment effect. The simultaneous saccharification and fermentation process was followed to determine the ethanol production of the pretreated biomass. The highest ethanol production yield based on initial weight was obtained from high treatment plotby Organosolv pretreatment with 1\% sulfuric acid (16.11\%). But regarding biomass production, medium treatment plot produced most, and bioethanol production was increased by $72.93 \%$ than control.
\end{abstract}

Keywords : slurry composting and biofiltration, yellow poplar (Liriodendron tulipifera), growth characteristics, organosolv pretreatment, bioethanol production

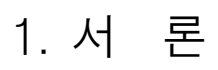

국제협약(런던협약 72) 발효에 따라 2012년부터 가축분뇨의 해양배출이 전면 금지되며 이에 경제적, 환경적 부담이 증가하고 있다. 이러한 문제점을 해결 하고 가축분뇨의 활용을 증대시키기 위해서 Slurry Composting and Biofiltration (SCB)액비가 개발되 었다(Park et al., 2008). SCB액비는 기존의 액비에 비해 저농도로, 무취, 균질성 및 청결성을 구비하고 있으며, 관비형태의 시비방법으로 인해 편리하게 시 용이 가능하다. $\mathrm{SCB}$ 액비는 벼에 최초로 적용되었으 며 배추, 고추 등의 작물에서 효과가 입증되어 보급 되었지만(Lim et al., 2008), 아직까지 목질계 바이 오매스에 대한 적용 및 효과의 입증은 전무하다.

목질계 바이오매스의 연간 생산량은 $1 \times 10^{10} \mathrm{MT}$ 이상으로 추정되며(Sanchez \& Cardona, 2008), 전 분계 바이오매스와는 달리 식량자원과의 경쟁이 없
고(Gray et al., 2006), 탄소 고정능력이 높아 (Fulton et al., 2004), 바이오에탄올이나 바이오오 일과 같은 대체 수송 연료를 생산할 수 있는 유일한 재생가능자원으로 인식되고 있다(Hamelinck et al., 2005). 하지만 높은 리그닌 함량과 화학적 구조의 문 제로 인해 당화 효소의 접근성이 떨어지므로 이를 향 상시키기 위한 전처리 공정이 필요하다(Saddler et al., 1993).

바이오에탄올 생산을 위한 바이오매스의 전처리 공정은 활발히 연구되어 왔으며(Wyman et al., 2005), 그 중 약산 전처리는 다양한 바이오매스에 대 해 폭넓게 적용되었다(Rocha et al., 2009; Saha et al., 2005). 약산 전처리는 Hemicellulose를 효과적으 로 분리해 내서 효소의 Cellulose로의 접근성을 높여 주는 장점을 가지고 있다(Emmel et al., 2003). 반면 에, 메탄올, 에탄올과 같은 유기용매에 무기촉매를 첨가해 처리하는 유기용매 전처리는 리그닌 함량이 
$\mathrm{SCB}$ 액비 처리량에 따른 백합나무의 생장 및 바이오에탄올 생산

Table 1. Characteristics of Slurry Composting and Biofiltration liquid fertilizer

\begin{tabular}{ccccccc}
\hline $\mathrm{pH}$ & Total N (\%) & Total P $(\mathrm{mg} / \mathrm{kg})$ & $\mathrm{Na}^{+}(\mathrm{mg} / \mathrm{kg})$ & $\mathrm{Mg}^{2+}(\mathrm{mg} / \mathrm{kg})$ & $\mathrm{K}^{+}(\mathrm{mg} / \mathrm{kg})$ & $\mathrm{Ca}^{2+}(\mathrm{mg} / \mathrm{kg})$ \\
\hline \hline $8.00 \pm 0.00$ & $0.07 \pm 0.01$ & $66.81 \pm 3.66$ & $200.73 \pm 7.41$ & $4.51 \pm 0.23$ & $918.37 \pm 24.13$ & $45.71 \pm 2.32$ \\
\hline
\end{tabular}

높은 목질계 바이오매스에 특히 효과적이다(Liu et al., 2000). 뿐만 아니라 유기용매 전처리를 통해 얻 어지는 유기용매 리그닌과 같은 부산물은 순도가 높 아 바이오리파이너리 공정으로의 적용에도 장점을 가지고 있다.

따라서 본 연구에서는 다른 수종에 비해 목재 구성 성분 중 Cellulose가 차지하는 비율이 높고, 벌기령 (약 20년)이 짧은 백합나무(Yellow poplar, Liriodendron tulipifera)에 SCB액비를 처리하고 바이오매스의 생 장특성을 평가하여 $\mathrm{SCB}$ 액비의 활용성 및 안정적인 목질계 바이오매스 공급 가능성을 탐색하고, 실제로 $\mathrm{SCB}$ 액비 처리된 바이오매스를 전처리한 후 동시당 화발효공정을 통해 바이오에탄올을 생산하여, $\mathrm{SCB}$ 액비 처리가 바이오에탄올 생산에 미치는 영향을 구 명하고자 하였다.

\section{2. 재료 및 방법}

\section{1. 공시재료}

본 연구의 공시재료는 백합나무 7년생으로써 국립 산림과학원 산림유전자원부에서 관리하고 있는 시험 지(경기도 화송시 매송면 어천리)에서 채취하였다. $\mathrm{SCB}$ 액비는 국립축산과학원에서 퇴비단 여과법 (Slurry Composting and Biofiltration)으로 제조한 액비를 제공받아 시험구에 시비하였으며, $\mathrm{SCB}$ 액비 의 이화학적인 특성은 Table 1 과 같다.

\section{2. 시험구 설정 및 $\mathrm{SCB}$ 액비 처리}

$\mathrm{SCB}$ 액비 처리량이 바이오매스 생장에 미치는 영 향을 확인하기 위해서 대조구, 소 처리구(10 L tree week $\left.^{-1}\right)$, 중 처리구 $\left(20 \mathrm{~L} \mathrm{tree} \mathrm{week}^{-1}\right)$, 대 처리구 $\left(30 \mathrm{~L} \mathrm{tree}^{-1}\right.$ week $\left.^{-1}\right)$ 를 설정하였다. 각 시험구에는
$16 \sim 18$ 개체의 백합나무가 분포하고 있으며, 시험구 별 영향을 배제하기 위하여 $10 \mathrm{~m}$ 간격으로 구분시켰 다. SCB액비는 2009년 6월부터 9월까지 시비하였다.

\section{3. 생장량 조사}

백합나무의 생장 조사를 위해 각 시험구별로 전자 식 캘리퍼스와 접자를 이용하여 수고 및 근원경을 측 정하여 비교하였으며, 측정한 시기는 2009년 6월 5 일, 7월 10일, 8월 4일, 9 월 18일이었다. 수고와 근원 경 수치를 이용하여 상대생장율(RGR: Relative Growth Rate)을 계산하고 시험구별 생장량을 비교 하였으며, 사용한 식은 다음과 같다.

$$
\begin{aligned}
\mathrm{RGR}= & \ln \left(\text { 생장 정지기의 } \mathrm{D}^{2} \cdot \mathrm{H}\right)-\ln (\text { 처리 개시 } \\
& \text { 기의 } \left.\mathrm{D}^{2} \cdot \mathrm{H}\right)
\end{aligned}
$$

또한 실제 바이오매스 생장량을 확인하기 위하여 $\mathrm{SCB}$ 액비 처리가 끝난 후 각각의 시험구에서 임의로 1 개체의 백합나무를 벌목하여 잎, 가지, 줄기의 무게 를 측정하고, 수간석해법을 이용하여 바이오매스의 부피를 추정하였다(Newton, 2003).

\section{4. 엽특성 조사}

엽면적은 생장이 일정한 상위 3 5엽째의 우량한 엽을 채취한 후 엽면적 측정기(Leaf area meter, LI$3100, \mathrm{LI}-\mathrm{COR}$ Inc., USA)를 이용하여 처리구별 수 종의 엽면적을 측정 비교하였고, 엽면적 측정 후 엽 의 생장량을 간접적으로 측정하기 위해 $85 \pm 5^{\circ} \mathrm{C}$ 에 서 3 시간 이상 건조한 후 무게를 측정하여 각 시험구 별로 비교하였다.

잎의 광합성 관련 색소 함량(엽록소 $\mathrm{a}, \mathrm{b}$, 카로티 
노이드)을 측정하기 위해서 3 5번째 생엽의 엽맥이 포함되지 않은 부분에서 콜크보러 9호로 샘플을 채 취하였다. 채취된 샘플은 $10 \mathrm{~m} \ell$ Dimethyl Sulfoxide (DMSO)에 담아 상온에서 7시간 동안 유지하여 색소 를 추출하였다. 추출액의 흡광도는 $480,649,665$ $\mathrm{nm}$ 의 파장에서 UV/VIS 분광광도계(Shimadzu2550 , Japan)로 측정하였다. 엽록소 $\mathrm{a}, \mathrm{b}$ 의 함량과 카로티노이드 함량은 Wellburn's methods을 이용하 여 산출하였으며, 측정된 값은 아래 공식을 사용하였 다(Wellburn, 1994).

$$
\begin{gathered}
\text { Chl } \mathrm{a}=12.19 \mathrm{~A}_{665}-3.45 \mathrm{~A}_{649} \\
\text { Chl } \mathrm{b}=21.99 \mathrm{~A}_{649}-5.32 \mathrm{~A}_{665} \\
\text { Carotenoid }=\left(1000 \mathrm{~A}_{480} 2.14 \mathrm{Chl} \text { a } 70.16 \mathrm{Chl} b\right) \\
\qquad / 220
\end{gathered}
$$

또한 총질소, 총인 및 치환성 양이온 $\left(\mathrm{Na}^{+}, \mathrm{Mg}^{2+}\right.$, $\left.\mathrm{K}^{+}, \mathrm{Ca}^{2+}\right)$ 등을 분석하였는데, 시험구별로 5 개체씩 잎을 채취하여 $80^{\circ} \mathrm{C}$ 에서 72 시간 건조시킨 후, 40 mesh로 분쇄하고 동일한 무게비로 혼합하여 3 반복 으로 분석을 실시하였다. 총질소는 서울대학교 농생 명과학공동기기원에서 보유한 켈달 단백질/질소 자 동분석기(Kjeldahl Protein/Nitrogen Analyzer, Kjeltec Auto 1035/1038 System, Tecator AB, Sweden)를, 총인과 치환성 양이온은 동일기관이 보유한 유도 결 합 플라즈마 발광광도기(ICP Emission Spectrometer, ICPS-1000IV, Shimadzu, Japan)를 사용하여 각각 측정하였다.

\section{5. 전처리 및 동시당화발효공정}

바이오매스 전처리 및 성분 분석은 바이오매스 생 장량을 측정하기 위해 채취한 백합나무 줄기를 처리 구 별로 나누어 충분히 건조시킨 후 40 mesh 이하로 분쇄한 목분을 이용하였으며 함수율은 $10 \%$ 이하로 조절하였다. 전처리 방법 및 첨가한 촉매가 바이오에 탄올 생산에 미치는 영향을 확인하기 위하여 전처리 방법 중 일반적으로 가장 많이 사용되는 약산 전처리 ( $1 \%$ 황산 수용액)와 가장 효과적인 전처리 방법으로
알려진 유기용매 전처리(50\% 에탄올, $\mathrm{w} / 1 \%$ 황산 또 는 $1 \%$ 수산화나트륨)를 이용하였다. 전처리는 내부 온도를 측정할 수 있는 $500 \mathrm{ml}$ 반응기에 목분 $20 \mathrm{~g}$ 과 전처리 용매 $200 \mathrm{~m} \ell$ 를 넣고 $150^{\circ} \mathrm{C}$ 에서 10 분간 진행 하였다. 승온시간은 약 40 분 정도로 조절하였으며 반응시간에 포함하지 않았다. 전처리 후 바로 상온으 로 냉각시켜서 전처리 산물을 증류수로 충분히 세척 한 후 $2 \mathrm{G} 2$ Glass filter (IWAKI)로 필터링하고 무게 를 측정하여 잔여율(Water Insoluble Solid (WIS) recovery rate)을 구하였다.

전처리 산물의 동시당화발효공정을 위해서 사용된 당화 효소로는 Cellulase (NS-50013)와 $\beta$-Glucosidase (NS-50010)를 이용하였고 모두 Novozyme Korea Ltd.에서 제공받았다. 발효균주로는 선배양된 Yeast (Sacharomyces cerevisiae ATTC® 26603)를 사용하 였다(Park et al., 2010). 동시당화발효는 $250 \mathrm{~m} \ell$ 삼 각플라스크에 전처리 산물 $5 \mathrm{~g}$ (전건 중량)과 Cellulase (30 FPU), $\beta$-Glucosidase (Cellulose 투입량의 0.3배 $(\mathrm{w} / \mathrm{w}))$, Yeast $(2 \mathrm{~g} / \mathrm{L})$ 를 투입한 후 $0.05 \mathrm{M}$ sodium acetate (pH 5.0)를 이용하여 최종 부피를 $50 \mathrm{~m}$ 로 맞추고 진탕배양기에서 $30^{\circ} \mathrm{C}, 150 \mathrm{rpm}$ 으로 72 시간 동안 동시당화발효 한 후 샘플링하여 HPLC로 에탄 올 함량을 분석하였다.

\section{6. 구성당 및 에탄올 분석}

구성당 및 에탄올 분석은 NREL Chemical Analysis and Testing Standard 방법으로(Sluiter et al., 2004), 서울대학교 농생명과학공동기기원에서 보유한 HPLC (Agilent LC1100, USA)를 이용하여 Glucose, Xylose, Ethanol 함량을 측정하였다. 이동상은 $0.01 \mathrm{~N}$ $\mathrm{H}_{2} \mathrm{SO}_{4}$, Column은 Aminex HPX-87H column (300 $\mathrm{mm} \times 7.8 \mathrm{~mm}, 5 \mu \mathrm{m}$ )을 사용하여 $0.5 \mathrm{ml} / \mathrm{min}$ 의 유속 으로 분석을 실시하였으며, 각 피크 검출에는 RI 검 출기(Agilent LC1100, USA)를 사용하였다.

\section{7. 통계 처리}

$\mathrm{SCB}$ 액비 처리량과 전처리 방법에 따른 전처리 효 


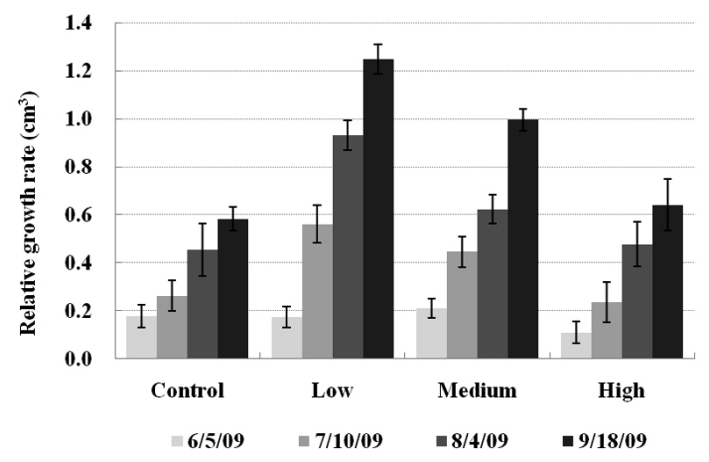

Fig. 1. Effect of SCBLF treatment amounts on relative growth rates $\left(\mathrm{cm}^{3}\right)$ of yellow poplar during the fertilizer treatment period.

SCBLF treatment: Slurry Composting and Biofiltration liquid fertilizer treatment

Low: 10 L tree week $^{-1}$; Medium: $20 \mathrm{~L}_{\text {tree }}$ week $^{-1}$; High: $30 \mathrm{~L}$ tree $^{-1}$ week ${ }^{-1}$.

과와 구성당 및 에탄올 생산량의 차이 등을 $\mathrm{SAS}$ programming package의 일반화선형모형으로 분석 하였다. $95 \%$ 신뢰구간이 모든 통계분석에서 이용되 었으며 최소유의차검정 (Least Significant Difference Test)를 실시한 후 $\mathrm{p}<0.05$ 이하의 중요한 영향은 서 로 다른 문자로 표현하였다.

\section{3. 결과 및 고찰}

\section{1. 바이오매스 생장}

$\mathrm{SCB}$ 액비 처리가 백합나무의 생장에 미치는 영향 을 확인하기 위하여 수고, 근원경 측정을 통한 상대 생장량을 비교, 평가하였다. 시비기간이 경과함에 따라 모든 처리구에서 상대 생장량이 증가하였고, $\mathrm{SCB}$ 액비 처리를 통해 대조구에 비해 상대 생장량이 높아졌다(Fig. 1). 하지만 SCB액비 처리량에 따라 상대 생장량이 증가하는 양상이 달랐다. 소 및 중 처 리구는 크게 증가한 반면 대 처리구의 경우 대조구와 큰 차이가 없었으며, 이는 과도한 $\mathrm{SCB}$ 액비 처리가 백합나무의 생장에 부정적인 영향을 주었거나 시험 구의 환경적인 요소에 따른 영향으로 사료된다.

보다 정확한 생장량 차이를 확인하기 위하여 백합

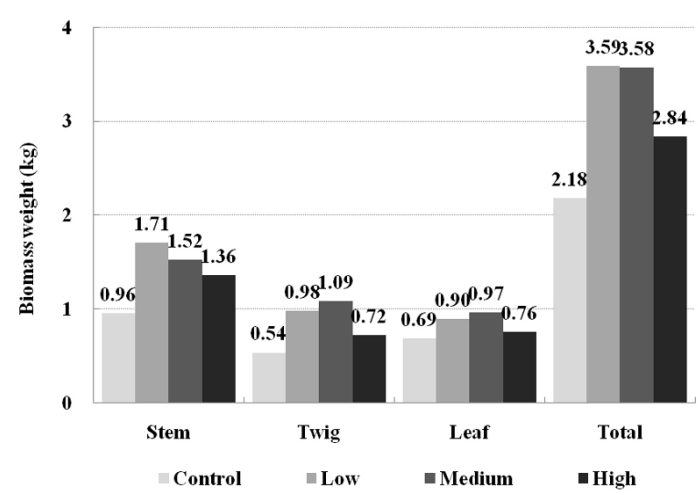

Fig. 2. Effect of SCBLF treatment amounts on biomass weight of yellow poplar.

SCBLF treatment: Slurry Composting and Biofiltration liquid fertilizer treatment.

Low: 10 L tree ${ }^{-1}$ week $^{-1}$; Medium: 20 L tree week $^{-1} ;$ High: $30 \mathrm{~L}$ tree $^{-1}$ week $^{-1}$.

나무의 바이오매스 생장량을 측정하였다. $\mathrm{SCB}$ 액비 처리 결과, 잎, 가지, 줄기 및 총 무게가 대조구에 비 해 크게 증가하였다(Fig. 2). SCB액비 처리량에 따 라서는 소 및 중 처리구의 바이오매스 생장량이 가장 크게 나타났으며 총 바이오메스 생장량은 대조구에 비해 약 $64.67 \%$ 증가하였다. 하지만 상대 생장량 결 과와 유사하게 대 처리구의 바이오매스 생장량은 중 처리구에 비해 감소하였다.

또한 수간석해를 통하여 수목의 재적 증가량을 측 정함으로써 $\mathrm{SCB}$ 액비 처리에 의한 일정기간 동안의 부피 생장량을 비교하였다. $\mathrm{SCB}$ 액비 처리를 통해 대 조구에 비해 부피생장이 증가하였고, 중 처리구의 2 년간 재적 증가량이 가장 크게 나타났으며 대조구 대 비 $70.10 \%$ 증가하였다(Fig. 3). 하지만 대 처리구에 서는 중 처리구에 비해 재적 증가량이 감소하였고 이 는 상대 생장량 및 바이오매스 생장량의 결과와 일치 하였다.

위의 결과를 종합하면, $\mathrm{SCB}$ 액비에 함유된 질소, 인, 치환성 양이온 등 다양한 무기원소들이 백합나무 의 생장에 긍정적인 영향을 주었다고 판단되며, $20 \mathrm{~L}$ tree $^{-1}$ week $^{-1}$ 수준의 SCB액비 처리는 바이오매스의 부피와 무게생장을 동시에 향상시켰으므로 백합나무 에 사용하기 적합하다. 


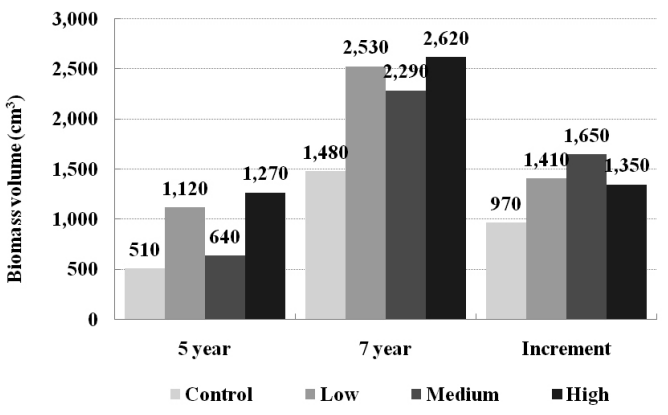

Fig. 3. Effect of SCBLF treatment amounts on biomass volume of yellow poplar for two years.

SCBLF treatment: Slurry Composting and Biofiltration liquid fertilizer treatment.

Low: $10 \mathrm{~L}$ tree ${ }^{-1}$ week $^{-1}$; Medium: $20 \mathrm{~L}$ tree $^{-1}$ week $^{-1}$; High: $30 \mathrm{~L}$ tree $^{-1}$ week $^{-1}$.

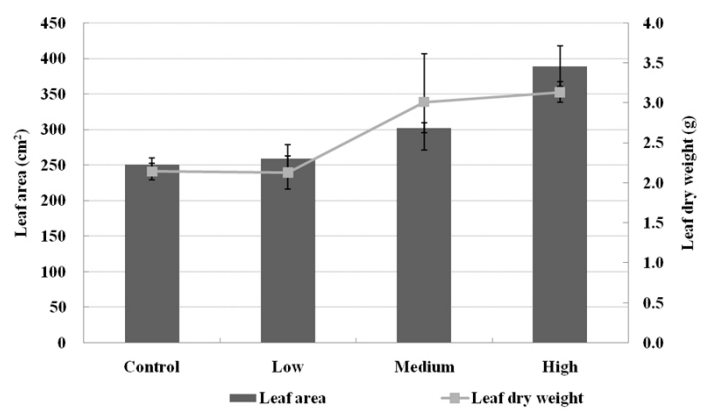

Fig. 4. Leaf area $\left(\mathrm{cm}^{2}\right)$ and dry weight $(\mathrm{g})$ of SCBLF treated yellow poplar.

SCBLF treatment: Slurry Composting and Biofiltration liquid fertilizer treatment.

Low: $10 \mathrm{~L}$ tree ${ }^{-1}$ week $^{-1}$; Medium: $20 \mathrm{~L}_{\text {tree }}$ week $^{-1}$; High: $30 \mathrm{~L}$ tree $^{-1}$ week $^{-1}$.

\section{2. 엽특성}

Fig. 4는 SCB액비 처리에 따른 백합나무 잎의 엽 면적과 건중량을 나타냈다. 엽면적과 건중량 모두 소 처리구에서는 대조구와 차이가 없었으나, 처리량이 증가함에 따라 크게 증가하였다. 바이오매스 생장 결 과와는 다르게 대 처리구에서 최대 엽면적(389.17 $\left.\mathrm{cm}^{2}\right)$ 과 건중량 $(3.14 \mathrm{~g})$ 을 얻을 수 있었으며 대조구 대비 각각 $54.83,46.44 \%$ 증가하였다. 하지만 엽면 적 $\left(\mathrm{cm}^{2}\right)$ 과 건중량 $(\mathrm{g})$ 으로부터 엽면적당 건중 $\left(\mathrm{g} / \mathrm{m}^{2}\right)$

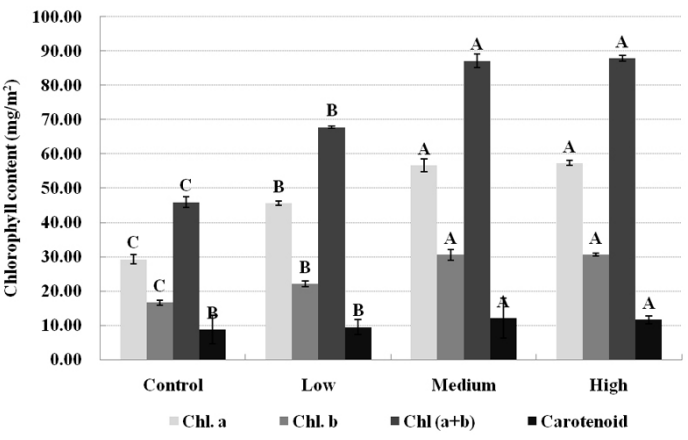

Fig. 5. Chlorophyll contents $\left(\mathrm{mg} / \mathrm{m}^{2}\right)$ of SCBLF treated yellow poplar leaves.

SCBLF treatment: Slurry Composting and Biofiltration liquid fertilizer treatment.

Low: $10 \mathrm{~L}^{-1}$ tree $^{-1}$ week ${ }^{-1}$; Medium: $20 \mathrm{~L}^{-1}$ tree $^{-1}$ week $^{-1}$; High: $30 \mathrm{~L}$ tree $^{-1}$ week $^{-1}$.

Chl. a: Chlorophyll a; Chl. b: Chlorophyll b; Chl. (a+b): Chlorophyll $(\mathrm{a}+\mathrm{b})$.

Different capital letters over the columns indicate significant difference at $\mathrm{p}=0.05$ (least significance difference test).

을 계산해 보면 중 처리구가 $99.56 \mathrm{~g} / \mathrm{m}^{2}$ 로 가장 높았 으며 대조구 대비 $16.81 \%$ 증가하였다. 따라서 중 처 리구에서 $\mathrm{SCB}$ 액비 처리를 통해 백합나무 잎의 동화 기관의 형태적 변화가 일어났다는 것을 의미하며, 이 는 바이오매스량이 증가하는 경향과 일치한다.

엽록소 함량은 수목의 생장과 매우 밀접한 관련이 있으므로 엽록소 $\mathrm{a}, \mathrm{b}$, 카로티노이드 등의 함량을 측 정함으로써 $\mathrm{SCB}$ 액비 처리가 백합나무의 생장에 미 치는 영향을 간접적으로 확인하였다(Fig. 5). $\mathrm{SCB}$ 액 비 처리는 백합나무 잎의 엽록소함량을 증가시켰으 며 처리량이 늘어남에 따라 엽록소 함량이 높아졌지 만 중 처리구와 대 처리구는 차이가 없었다. 이러한 결과는 바이오매스 생장 결과와 일치하였으며, 엽록 소 함량은 질소 비료 처리를 통해 증가한다는 이전의 결과와 비교해 보면(Bak \& Lee, 2001), SCB액비에 함 유된 질소 성분이 백합나무의 엽록소 함량 및 바이오 매스 생장을 증가시켰다고 판단된다. 다만 중 처리구 와 대 처리구간에 엽록소 함량에 차이가 없었고, 바 이오매스 생장에는 오히려 역효과를 나타내었으므 로, $\mathrm{SCB}$ 액비 처리량은 $20 \mathrm{~L} \mathrm{tree}^{-1} \mathrm{week}^{-1}$ 수준으로 조절하는 것이 필요하다.

잎의 총 질소, 총 인, 치환성 양이온 함량을 분석한 
$\mathrm{SCB}$ 액비 처리량에 따른 백합나무의 생장 및 바이오에탄올 생산

Table 2. Total nitrogen, total phosphorus and exchangeable cation contents $(\mathrm{g} / \mathrm{kg})$ of SCBLF treated yellow poplar leaves

\begin{tabular}{ccccccc}
\hline Treatment & T-N $(\%)$ & T-P $(\mathrm{g} / \mathrm{kg})$ & $\mathrm{Na}^{+}(\mathrm{g} / \mathrm{kg})$ & $\mathrm{Mg}^{2+}(\mathrm{g} / \mathrm{kg})$ & $\mathrm{K}^{+}(\mathrm{g} / \mathrm{kg})$ & $\mathrm{Ca}^{2+}(\mathrm{g} / \mathrm{kg})$ \\
\hline \hline Control & $1.59 \pm 0.08$ & $1.36 \pm 0.07$ & ND & $6.21 \pm 0.08$ & $15.75 \pm 0.19$ & $40.53 \pm 0.99$ \\
Low & $2.07 \pm 0.01$ & $1.54 \pm 0.06$ & ND & $8.80 \pm 0.47$ & $11.60 \pm 0.34$ & $38.07 \pm 0.12$ \\
Medium & $2.09 \pm 0.10$ & $1.14 \pm 0.01$ & ND & $2.27 \pm 0.00$ & $9.96 \pm 0.03$ & $10.47 \pm 0.08$ \\
High & $2.31 \pm 0.07$ & $1.26 \pm 0.02$ & ND & $2.46 \pm 0.05$ & $12.34 \pm 0.25$ & $11.61 \pm 0.01$ \\
\hline
\end{tabular}

Low: $10 \mathrm{~L}$ tree ${ }^{-1}$ week $^{-1}$; Medium: $20 \mathrm{~L}$ tree $^{-1}$ week $^{-1}$; High: $30 \mathrm{~L}_{\text {tree }}^{-1}$ week $^{-1}$.

T-N: Total nitrogen; T-P: Total phosphorus; ND: Not detected.

Table 3. Initial sugar contents and water insoluble solid recovery (\%) after each pretreatment of yellow poplar

\begin{tabular}{|c|c|c|c|c|c|}
\hline \multirow{3}{*}{ SCBLF treatment ${ }^{\mathrm{a}}$} & \multicolumn{2}{|c|}{ Sugar contents (\%) } & \multicolumn{3}{|c|}{ WIS recovery $(\%)^{b}$} \\
\hline & \multirow{2}{*}{ Glucose } & \multirow{2}{*}{ Xylose } & \multicolumn{2}{|c|}{ Organosolv pretreatment } & \multirow{2}{*}{$\begin{array}{c}\text { Dilute acid pretreatment } \\
1 \% \mathrm{H}_{2} \mathrm{SO}_{4} \\
\end{array}$} \\
\hline & & & $1 \% \mathrm{H}_{2} \mathrm{SO}_{4}$ & $1 \% \mathrm{NaOH}$ & \\
\hline Control & $48.94 \pm 0.01^{(\mathrm{C})}$ & $16.30 \pm 0.26^{(\mathrm{B})}$ & $47.89 \pm 0.31^{(\mathrm{D})}$ & $73.68 \pm 0.02^{(\mathrm{C})}$ & $63.38 \pm 0.65^{(C D)}$ \\
\hline Low & $49.50 \pm 1.61^{(\mathrm{BC})}$ & $16.03 \pm 0.55^{(\mathrm{B})}$ & $45.89 \pm 0.07^{(\mathrm{C})}$ & $72.28 \pm 0.25^{(A)}$ & $60.06 \pm 1.17^{(\mathrm{A})}$ \\
\hline Medium & $51.91 \pm 0.27^{(\mathrm{A})}$ & $17.10 \pm 0.02^{(A)}$ & $44.81 \pm 0.26^{(\mathrm{A})}$ & $73.19 \pm 0.35^{(\mathrm{B})}$ & $62.40 \pm 0.41^{(B)}$ \\
\hline High & $51.30 \pm 1.72^{(\mathrm{AB})}$ & $16.90 \pm 0.17^{(A)}$ & $46.47 \pm 0.45^{\text {(B) }}$ & $74.53 \pm 0.23^{(\mathrm{D})}$ & $63.85 \pm 0.88^{(\mathrm{D})}$ \\
\hline
\end{tabular}

Different capital letters in parenthesis indicate significant difference at $\mathrm{p}=0.05$ (least significance difference test).

${ }^{a}$ Low: $10 \mathrm{~L}$ tree ${ }^{-1}$ week $^{-1}$; Medium: $20 \mathrm{~L}_{\text {tree }}^{-1}$ week $^{-1}$; High: $30 \mathrm{~L}_{\text {tree }}^{-1}$ week $^{-1}$.

b Water insoluble solid recovery after each pretreatment.

결과(Table 2), 잎의 총질소 함량은 SCB액비 처리를 통해 크게 증가하였으며, 이는 엽록소 함량 및 바이 오매스 생산 결과를 뒷받침한다. 한편 일반적으로 무 기원소의 함량은 수목의 생장에 긍정적인 영향을 끼 치는데(Bilodeau-Gauthier et al., 2010), 총 인 함량 과 치환성 양이온인 $\mathrm{Na}^{+}, \mathrm{Mg}^{2+}, \mathrm{K}^{+}, \mathrm{Ca}^{2+}$ 함량은 중 처리구에서 가장 낮았다. 이는 잎 보다는 목부 생장 에 중요한 영향을 끼치는 무기원소들이 잎까지 도달 하지 않고 목부 생장에 충분히 사용되었기 때문으 로 예상되지만 추가 연구와 고찰이 필요하다고 사 료된다.

\section{3. 구성당 생산 및 전처리 효율}

$\mathrm{SCB}$ 액비 처리에 의하여 구성당인 Glucose와 Xylose 함량 모두 처리량이 늘어남에 따라 증가하였
고 중 처리구와 대 처리구는 차이가 없었다(Table 3). 이는 $\mathrm{SCB}$ 액비 처리를 통해 바이오매스 생장이 증진되면서 일어난 결과로 보이며, 고추에 $\mathrm{SCB}$ 액비 를 처리하였을 때 시용 수준 증가에 따른 당 함량의 증가를 보였다는 결과와 일치하였다(Lim et al., 2008). 전처리 효율은 전처리 후 남아있는 고형분의 비율인 잔여율로 간접적으로 측정하였는데 유기용매 전처리 $(\mathrm{w} / 1 \%$ 황산)의 효율이 가장 높았고 약산 전 처리, 유기용매 전처리 $(\mathrm{w} / 1 \%$ 수산화나트륨) 순이었 다. 소 처리구 및 중 처리구의 전처리 효율이 전반적 으로 가장 높았고, 중 처리구를 유기용매 전처리 (w/1\% 황산) 하였을 때 잔여율이 $44.81 \%$ 로 가장 높 은 전처리 효율을 보였다. $\mathrm{Mg}^{2+}$ 와 같은 치환성 양이 온은 유기용매 전처리 효율에 영향을 끼칠 수 있다는 이전의 결과를 고려하면(Park et al., 2010), 동일한 조건에서 더 높은 전처리 효율을 보이는 결과는 잎의 
Table 4. Ethanol production amount $(\mathrm{g} / \mathrm{L})$ of SCBLF treated yellow poplar after each pretreatment

\begin{tabular}{|c|c|c|c|c|}
\hline \multirow{2}{*}{ SCBLF treatment* } & \multirow{2}{*}{ Untreated } & \multicolumn{2}{|c|}{ Organosolv pretreatment } & \multirow{2}{*}{$\frac{\text { Dilute acid pretreatment }}{1 \% \mathrm{H}_{2} \mathrm{SO}_{4}}$} \\
\hline & & $1 \% \mathrm{H}_{2} \mathrm{SO}_{4}$ & $1 \% \mathrm{NaOH}$ & \\
\hline Control & $0.45 \pm 0.07$ & $30.85 \pm 0.25^{(\mathrm{C})}$ & $16.77 \pm 0.19^{(\mathrm{C})}$ & $19.78 \pm 0.03^{(\mathrm{B})}$ \\
\hline Low & $0.20 \pm 0.04$ & $32.39 \pm 0.05^{(\mathrm{B})}$ & $16.83 \pm 0.44^{(\mathrm{C})}$ & $19.99 \pm 0.95^{(\mathrm{B})}$ \\
\hline Medium & $0.25 \pm 0.02$ & $34.82 \pm 0.02^{(\mathrm{A})}$ & $18.96 \pm 0.58^{(\mathrm{A})}$ & $20.92 \pm 0.45^{(\mathrm{A})}$ \\
\hline High & $1.70 \pm 0.07$ & $34.66 \pm 0.16^{(\mathrm{A})}$ & $17.50 \pm 0.04^{(\mathrm{B})}$ & $21.01 \pm 0.03^{(\mathrm{A})}$ \\
\hline
\end{tabular}

Different capital letters in parenthesis indicate significant difference at $\mathrm{p}=0.05$ (least significance difference test).

${ }^{*}$ Low: $10 \mathrm{~L}$ tree week $^{-1}$; Medium: $20 \mathrm{~L}_{\text {tree }}^{-1}$ week $^{-1}$; High: $30 \mathrm{~L}^{-1}$ tree $^{-1}$ week $^{-1}$.

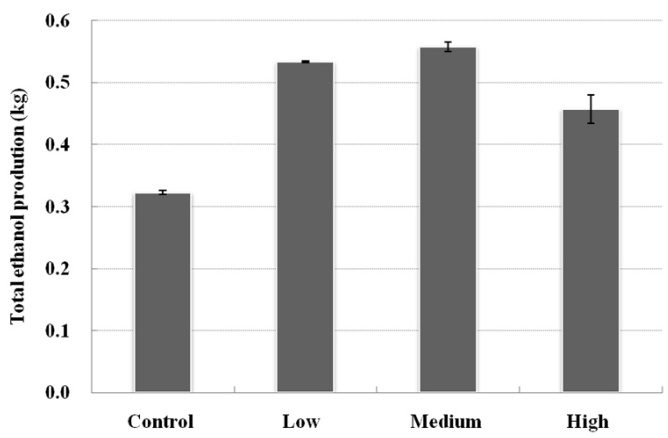

Fig. 6. Total ethanol production of SCBLF treated yellow poplar pretreated by organosolv $\left(\mathrm{w} / 1 \% \mathrm{H}_{2} \mathrm{SO}_{4}\right)$.

SCBLF treatment: Slurry Composting and Biofiltration liquid fertilizer treatment.

Low: $10 \mathrm{~L}$ tree ${ }^{-1}$ week $^{-1}$; Medium: $20 \mathrm{~L}_{\text {tree }}^{-1}$ week $^{-1}$; High: $30 \mathrm{~L}_{\text {tree }}^{-1}$ week ${ }^{-1}$.

무기원소 함량 결과에서 유추한대로 목부 내의 무기 원소 함량의 차이 때문으로 보이며, 이에 따라 $\mathrm{SCB}$ 액비 처리를 통해 전처리 효율이 높아졌다고 사료된다.

\section{4. 에탄올 생산 및 수율}

Table 4는 전처리 산물의 동시당화발효공정을 통 한 바이오에탄올 생산량을 나타냈다 $\mathrm{SCB}$ 액비 처리 를 통해 백합나무의 구성당 함량이 늘어나고 전처리 공정을 통해 효소의 접근성이 높아짐에 따라 에탄올 생산량이 크게 증가하였으며 구성당 생산 및 전처리 효율 결과와 일치하였다. $\mathrm{SCB}$ 액비 처리구별로는 중 처리구의 에탄올 생산량이 가장 높았고, 전처리 방법
별로는 유기용매 전처리 $(\mathrm{w} / 1 \%$ 황산 $)>$ 약산 전처리 $>$ 유기용매 전처리 (w/ $1 \%$ 수산화나트륨) 순이었다. 결과적으로 Glucose 생산량이 가장 많은 중 처리구 를 전처리 효율이 가장 높은 유기용매 전처리 $(\mathrm{w} / 1 \%$ 황산)하였을 때 최대 에탄올 $(34.82 \mathrm{~g} / \mathrm{L})$ 이 생산되었 고 대조구 대비 약 $12.87 \%$ 증가하였다.

이에 반해, Glucose 대비 이론적 에탄올 수율과 잔 여율을 고려한 초기 투입량 대비 에탄올 수율은 대 처리구 바이오매스를 유기용매 전처리 (w/ $1 \%$ 황산) 하였을 때 각각 $62.05 \%, 16.11 \%$ 로 가장 높게 나타났 다. 하지만 바이오매스 생장량을 고려하면(중 처리 구: $3.58 \mathrm{~kg}$, 대 처리구: $2.84 \mathrm{~kg}$ ) 중 처리구의 에탄 올 생산량이 가장 높았으며 대조구 대비 $72.93 \%$ 증 가하였다(Fig. 6). 백합나무로부터 얻어진 초기 투입 량 대비 에탄올 수율은 Corn stover나 유채대 등으로 부터 얻어진 결과에 비하면 다소 낮지만(Lu et al., 2009; Sanchez \& Cardona, 2008) 탄소고정 능력 등 과 같은 목질계 바이오매스의 장점을 고려하면 바이 오에탄올 생산을 위한 보다 실용적인 원료라고 사료 된다. 한편 유기용매 전처리 (w/ $1 \%$ 수산화나트륨)의 전처리 효율은 약산 전처리에 비해 $10 \%$ 이상 낮았지 만 에탄올 생산량에서는 거의 차이가 없었고 이로 인 해 에탄올 수율이 더 높아졌다. 이 결과는 $\mathrm{SCB}$ 액비 처리를 통해 시료 내의 무기원소 함량이 높아진 조건 에서는 약산 전처리보다 유기용매 전처리의 효율이 높아질 수 있음을 의미하여 Acid-free 전처리 가능성 또한 확인할 수 있었다. 
$\mathrm{SCB}$ 액비 처리량에 따른 백합나무의 생장 및 바이오에탄올 생산

Table 5. Ethanol production yield of SCBLF treated yellow poplar after each pretreatment

\begin{tabular}{|c|c|c|c|c|c|c|}
\hline \multirow{3}{*}{ SCBLF treatment ${ }^{\mathrm{a}}$} & \multicolumn{3}{|c|}{ Yield / glucose theoretical (\%) } & \multicolumn{3}{|c|}{ Yield / initial weight $(\%)^{c}$} \\
\hline & \multicolumn{2}{|c|}{ Organosolv pretreatment } & \multirow{2}{*}{$\begin{array}{c}\begin{array}{c}\text { Dilute acid } \\
\text { pretreatment }\end{array} \\
1 \% \mathrm{H}_{2} \mathrm{SO}_{4} \\
\end{array}$} & \multicolumn{2}{|c|}{ Organosolv pretreatment } & \multirow{2}{*}{$\begin{array}{c}\begin{array}{c}\text { Dilute acid } \\
\text { pretreatment }\end{array} \\
1 \% \mathrm{H}_{2} \mathrm{SO}_{4}\end{array}$} \\
\hline & $1 \% \mathrm{H}_{2} \mathrm{SO}_{4}$ & $1 \% \mathrm{NaOH}$ & & $1 \% \mathrm{H}_{2} \mathrm{SO}_{4}$ & $1 \% \mathrm{NaOH}$ & \\
\hline Control & $59.20 \pm 0.09$ & $45.51 \pm 0.56$ & $50.22 \pm 0.45$ & $14.78 \pm 0.03^{(\mathrm{C})}$ & $12.36 \pm 0.14^{(\mathrm{GH})}$ & $12.53 \pm 0.11^{(\mathrm{G})}$ \\
\hline Low & $58.90 \pm 1.93$ & $48.23 \pm 2.66$ & $47.58 \pm 2.88$ & $14.86 \pm 0.00^{(\mathrm{C})}$ & $12.17 \pm 0.27^{(\mathrm{HI})}$ & $12.00 \pm 0.34^{(\mathrm{I})}$ \\
\hline Medium & $58.94 \pm 0.62$ & $52.41 \pm 2.12$ & $49.29 \pm 0.49$ & $15.60 \pm 0.08^{(B)}$ & $13.87 \pm 0.49^{(\mathrm{D})}$ & $13.05 \pm 0.20^{(\mathrm{F})}$ \\
\hline High & $62.05 \pm 1.86$ & $50.26 \pm 2.19$ & $51.67 \pm 1.65$ & $16.11 \pm 0.23^{(\mathrm{A})}$ & $13.04 \pm 0.01^{(\mathrm{F})}$ & $13.41 \pm 0.17^{(\mathrm{E})}$ \\
\hline
\end{tabular}

Different capital letters in parenthesis indicate significant difference at $\mathrm{p}=0.05$ (least significance difference test).

${ }^{a}$ Low: $10 \mathrm{~L}$ tree ${ }^{-1}$ week $^{-1}$; Medium: $20 \mathrm{~L}_{\text {tree }}$ $^{-1}$ week $^{-1}$; High: $30 \mathrm{~L}$ tree week $^{-1}$.

b Theoretical ethanol production yields based on initial glucose contents.

${ }^{c}$ Actual ethanol production yields based on initial input weight.

\section{4. 결 론}

본 연구의 결과를 종합하면 $\mathrm{SCB}$ 액비 처리를 통해 목부 내에 질소, 인, 치환성 양이온 등과 같은 양료원 소가 흡수되어 백합나무의 엽특성이 향상되었고, 이 에 따라 상대 생장량도 증가시킨 것으로 판단된다. 또한 상대 생장량의 증가를 통해 백합나무 바이오매 스의 생장량이 늘어났고 특히 Glucose, Xylose의 함 량을 증가시켰다. 뿐만 아니라 치환성 양이온은 바이 오매스 전처리 효율의 향상에도 영향을 끼쳤으리라 고 예상되어 결과적으로 더 많은 에탄올을 생산할 수 있었다. 따라서 백합나무 조림지에 화학비료가 아닌 $\mathrm{SCB}$ 액비를 사용함으로써 가축분뇨의 해양배출 금지 에 대비하여 그 활용 가능성을 증대시킴과 동시에 효 과적인 바이오매스 및 바이오에탄올 생산 가능성을 확인할 수 있었다. 하지만 과도한 $\mathrm{SCB}$ 액비 처리는 역효과를 나타냈으므로 수목 생장이나 토양환경 등 에 미치는 영향을 구명하기 위해서는 보다 장기간의 시험이 요구되며 이를 통해 적정 처리량을 결정하는 등에 관한 추가적인 연구가 필요한 것으로 판단된다.

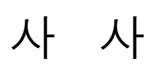

본 연구는 농촌진흥청 '공동연구사업(과제번호 : 2010030103007800106)' 및 산림청 '산림과학기술개 발사업(과제번호 : S120810L140130)'의 지원에 의하
여 이루어진 것입니다.

\section{참 고 문 헌}

1. Bak, J. H. and K. J. Lee. 2001. Effects of Nitrogen and phosphorus Fertilization on the Growth, Carbohydrate Contents and photosynthesis of Pinus densiflora Seedlings Exposed to Ozone in an Open - Top Chamber. Journal of Korean Forest Society 90(3): 306 313.

2. Bilodeau-Gauthier, S., D. Houle, C. Gagnon, B. Cote, and C. Messier. 2010. Assessment of sugar maple tree growth in relation to the partitioning of elements in xylem along a soil acidity gradient. Forest Ecology and Management.

3. Emmel, A., A. L. Mathias, F. Wypych, and L. P. Ramos. 2003. Fractionation of Eucalyptus grandis chips by dilute acid-catalysed steam explosion. Bioresource Technology 86(2): 105 115.

4. Fulton, L., T. Howes, and J. Hardy. 2004. Biofuels for transport: an international perspective. OECD, International Energy Agency.

5. Gray, K. A., L. Zhao, and M. Emptage. 2006. Bioethanol. Current Opinion in Chemical Biology 10(2): 141 146.

6. Hamelinck, C., G. Hooijdonk, and A. Faaij. 2005. Ethanol from lignocellulosic biomass: technoeconomic performance in short-, middle-and long-term. Biomass and Bioenergy 28(4): 384 410.

7. Lim, T. J., S. D. Hong, S. H. Kim, and J. M. Park. 


\section{김호용 - 곽기섭 · 김혜연 · 유근옥 - 김판기 · 조도현 · 최진용 · 최인규}

2008. Evaluation of Yield and Quality from Red Pepper for Application Rates of Pig Slurry Composting Biofiltration. Korean Journal of Environmental Agriculture 27(2): 171 177.

8. Liu, Y., S. Carriero, K. Pye, and D. S. Argyropoulos. 2000. A comparison of the structural changes occurring in lignin during Alcell and kraft pulping of hardwoods and softwoods. American Chemical Society, USA, Washington DC.

9. Lu, X., Y. Zhang, and I. Angelidaki. 2009. Optimization of H2SO4-catalyzed hydrothermal pretreatment of rapeseed straw for bioconversion to ethanol: Focusing on pretreatment at high solids content. Bioresource technology 100(12): 3048 $\sim 3053$.

10. Newton, P. F. 2003. Stem analysis program for coniferous forest tree species. Computers and Electronics in Agriculture 39(1): 61 66.

11. Park, J. H., J. K. Yeo, Y. B. Koo, W. W. Lee, H. C. Kim, and C. H. Park. 2008. Effects of Slurry Composting and Biofiltration Liquid Fertilizer on Growth Characteristic of Poplar Clones in a Reclaimed Land Mounding Soil. Korean Journal of Soil Science and Fertilizer 41(5): 318 323.

12. Park, N., H. Kim, B. Koo, H. Yeo, and I. Choi. 2010. Organosolv pretreatment with various catalysts for enhancing enzymatic hydrolysis of pitch pine (Pinus rigida). Bioresource technology 101: 7046 7053.

13. Rocha, M., T. Rodrigues, G. de Macedo, and L.
Goncalves. 2009. Enzymatic Hydrolysis and Fermentation of Pretreated Cashew Apple Bagasse with Alkali and Diluted Sulfuric Acid for Bioethanol Production. Applied biochemistry and biotechnology 155(1): 104 114.

14. Saddler, J. N., L. P. Ramos, and C. Breuil. 1993. Bioconversion of Forest and Agricultural Plant Wastes. CAB International, London, UK, 73 92.

15. Saha, B., L. Iten, M. Cotta, and Y. Wu. 2005. Dilute acid pretreatment, enzymatic saccharification and fermentation of wheat straw to ethanol. Process Biochemistry 40(12): 3693 3700.

16. Sanchez, O. and C. Cardona. 2008. Trends in biotechnological production of fuel ethanol from different feedstocks. Bioresource technology 99(13): $5270 \sim 5295$.

17. Sluiter, A., B. Hames, R. Ruiz, C. Scarlata, J. Sluiter, D. Templeton, and D. Crocker. 2004. Determination of structural carbohydrates and lignin in biomass. NREL, Golden, CO.

18. Wellburn, A. 1994. The spectral determination of chlorophylls a and b, as well as total carotenoids, using various solvents with spectrophotometers of different resolution. Plant Physiology 144: 307 $\sim 313$.

19. Wyman, C. E., B. E. Dale, R. T. Elander. M. Holtzapple, M. R. Ladisch, and Y. Y. Lee. 2005. Coordinated development of leading biomass pretreatment technologies. Bioresource technology 96(18): 1959 1966. 